\title{
新时期我国战略性新兴产业发展宏观研究
}

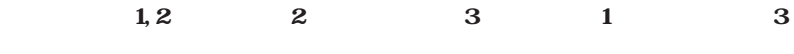 \\ （1. 清华大学社会科学学院，北京 $100084 ； 2$. 中国工程院战略咨询中心，北京 $100088 ;$ \\ 3. 中国工程物理研究院，北京 100083）
}

摘要: 战略性新兴产业在我国现代产业体系中的地位和对经济高质量发展的贡献越来越显著。面对复杂的国内外环境和即将 进入 “十四五” 的新形势, 迫切需要对我国战略性新兴产业进行宏观思考和战略定位研究。本文深入分析发达国家新兴产业 发展态势, 总结我国战略性新兴产业发展成绩以及面临的挑战和问题, 论证我国相关产业发展的紧迫性和重要性, 在此基础 上形成了产业发展的总体思路。研究认为, 应继续将培育和发展战略性新兴产业作为国家现代产业体系的重要方面, 准确识 别相关产业的关键短板技术, 科学分类并进行顶层部署, 尤其是要谋划好产业区域布局以针对性培育产业集群。研究建议: 将战略性新兴产业作为国家 “十四五” 规划的重要内容, 出台新兴产业发展专项规划; 结合新兴产业发展需求, 深入探索新 时代举国体制、人才激励与共享机制。

关键词: 战略性新兴产业; 宏观研究; 产业体系; 产业集群

中图分类号：F420 文献标识码：A

\section{A Macro-study on the Development of China's Strategic Emerging Industries in the New Era}

\author{
Liu Xiaolong ${ }^{1,2}$, Ge Qin ${ }^{2}$, Cui Leilei ${ }^{3}$, Li Bin ${ }^{1}$, Du Xiangwan ${ }^{3}$ \\ (1. School of Social Sciences, Tsinghua University, Beijing 100084, China; 2. Center for Strategic Studies, Chinese Academy of \\ Engineering, Beijing 100088, China; 3. Chinese Academy of Engineering Physics, Beijing 100083, China)
}

\begin{abstract}
The status of strategic emerging industries in China's modern industrial system and their contribution to high-quality economic development are becoming increasingly significant. In face of complex domestic and international environments and the situation that China is about to enter the 14th Five-Year Plan period, it is urgently necessary to make macro thinking of China's strategic emerging industries and study their strategic positioning. The paper carefully analyzes the development situation of emerging industries in developed countries; examines the achievements, challenges, and problems of emerging industries in China; demonstrates the urgent needs and importance of accelerating the development of relevant industries in China; and outlines a general idea about the development in China. China should regard the cultivation and development of strategic emerging industries as an important component of the national modern industrial system; ensure the identification, classification, and strategic deployment of the weaknesses in technologies in the industries; and scientifically plan the regional layout of strategic emerging industries, thus to cultivate industrial clusters at the national level. Conclusively the paper suggests that China should include strategic emerging industries in the national 14th Five-Year Plan; issue a special plan for their development; and explore an integrated national system and a talent motivation and sharing mechanism.
\end{abstract}

Keywords: strategic emerging industries; macro-study; industrial system; industrial clusters

收稿日期 : 2020-01-03; 修回日期 : 2020-03-04

通讯作者: 杜祥琬, 中国工程物理研究院高级科学顾问, 中国工程院院士, 研究方向为应用物理学和工程科技战略; E-mail: duxw@cae.cn 资助项目：中国工程院咨询项目“新兴产业发展战略研究（2035）”(2018-ZD-12)

本刊网址：www.engineering.org.cn/ch/journal/sscae 


\section{一、前言}

当前, 新一轮科技革命和产业革命加速推进, 呈现出许多新特征, 产业形态、核心要素和竞争范 式正在发生深刻变化。全球科技创新已进入多点突 破、群体迸发的新阶段, 颠覆性技术不断涌现, 催 生新技术、新业态、新模式，对传统生产方式和生 活方式构成前所未有的深刻影响。世界主要经济体 继续将大力推动新兴产业发展作为国家或地区重要 战略，同时采取加大科技投入、鼓励科技创新的主 要发展策略。美国发布了《量子信息科学国家战略 概述》, 认为量子信息科技引领新一轮技术革命, 将给国家安全、经济发展、基础科研等带来重大 变革。同时, 美国提出了发展第五代移动通信技术 $(5 \mathrm{G})$ 与农村联网、先进制造、人工智能 $(\mathrm{AI})$ 、先 进交通运输、网络安全、数字经济等国家战略。日 本将物联网、 $\mathrm{AI}$ 和机器人作为第四次产业革命的 核心，在国家层面建立了完整的研发促进机制，同 时加大对航空航天产业和氢燃料应用产业的扶持力 度。英国确立了引领全球技术革命、面向未来产业 前沿的 4 项重大挑战, 即 $\mathrm{AI}$ 与数字经济、清洁发展、 未来交通运输、老龄化社会。德国旨在确保或重夺 相关领域在欧洲乃至全球的经济技术实力、竞争力 和工业领先地位。

改革开放 40 多年来, 我国经济飞速发展, 已 经建立了较为全面的产业体系。然而, 我国庞大的 产业体系仍处于全球价值链的中低端, 关键核心技 术缺失严重, 进而威胁到产业安全。战略性新兴产 业代表了新一轮科技革命和产业变革的方向，近年 来表现出强劲的发展势头。继续发展战略性新兴产 业对我国实现 “两个一百年” 奋斗目标，抢占国际 科技和产业制高点至关重要。学术界对战略性新兴 产业发展进行了大量研究, 大致分为三方面。一是 $\mathrm{AI}$ 、新能源和数字创意等具体产业角度 [1 3]; 二 是从长江三角洲、珠江三角洲、京津冀等区域战略 性新兴产业发展角度 [4,5]; 三是从战略性新兴产业 的政策支持和导向角度 [6,7]。这些研究提出了很多 创新的路径、观点和措施, 但在新形势下缺乏从国 家战略高度、从战略性新兴产业整体层面进行的宏 观研究。为此, 本文在广泛调研和项目研究的基础 上，从战略、宏观和前瞻角度对我国战略性新兴产 业发展进行了思考和分析。

\section{二、战略性新兴产业进展和面临的问题}

我国高度重视战略性新兴产业的发展，密集 出台了多项政策文件。在国家和地方政府宏观政策 的影响下，在企业和资本市场的配合下，战略性新 兴产业发展呈现出规模不断壮大、重点领域增长强 劲、要素高效聚集、创新能力持续提升以及政策环 境不断完善等鲜明特征，充分发挥了引领经济高质 量发展的引擎作用。到 “十二五” 末，战略性新 兴产业增加值占国内生产总值（GDP）比重达到 $8 \%$, 顺利完成了既定目标, 并且涌现出大批新技 术、新产品、新模式、新业态，成为稳增长、促 改革、调结构、惠民生的有力支撑。2015-2018 年， 战略性新兴产业规模以上工业增加值年均增速达 到 $10.1 \%$, 高于同期规模以上全国整体工业增加值 3.8 个百分点; 战略性新兴产业规模以上服务业企 业营业收入年均增速为 $15.7 \%$ ，高于同期全国规模 以上服务业企业营业收入 3.7 个百分点 $[8]$ 。数字 经济、工业互联网、AI 等关键技术取得重大突破, 新一代移动通信、光伏和核电等产业达到世界领 先水平; 新模式和新业态不断涌现, 产业跨界融 合发展趋势越发明显, 形成了一批具有特色、优 势明显的产业集群。此外，配套的产业促进政策 体系初步形成。

我国战略性新兴产业在发展中也存在一些问 题，产业规模较 “十三五” 时期制定的目标还有 一定差距。

\section{（一）国家和地方政策统筹不够，造成产业同质化} 严重、产能过剩

战略性新兴产业主要包括新一代信息技术、高 端装备制造、生物、绿色低碳和数字创意等五大产 业，全国各省、市、自治区战略性新兴产业的发展 重点基本上都围绕这五大产业展开。然而，由于国 家和地方政策统筹性不够，地方政府较多从自身角 度出发进行布局和谋划, 从而造成了部分战略性新 兴产业同质化严重、产能过剩，而其他产业及重大 关键技术缺位等问题。有些地方政府未能清楚认识 各个产业的发展重点, 机械地将各类项目纳入战略 性新兴产业规划。有些地方政府虽然发展战略性新 兴产业的积极性很高, 但限于思维定势, 在战略性 新兴产业发展思路方面仍然延续传统产业发展的老 
办法; 投入的大量资金往往流入后端的制造环节， 甚至直接去购买国外的生产线, 与此同时很多高端 产品仍然严重依赖进口。

\section{（二）我国建立了比较完整的产业体系, 但大而不 强的问题较为突出}

自中美贸易摩擦以来, 国内更清楚地认识到 我国各产业链存在的短板环节, 关键核心技术和 “卡脖子” 技术受制于人的现象突出。首先, 部分 产业尚有大量核心瓶颈环节有待突破, 例如, 高 性能航空发动机、高端芯片等重点产品长期依赖 进口, 尚不具备自主生产能力; 其次, 核心基础 零部件、先进基础工艺、关键基础材料等产业基 础能力较为薄弱, 产业升级发展能力距离自主可 控尚有较大差距; 最后, 新兴产业自主创新能力 有待进一步提高, 在基础科学研究投入、科学基 础设施建设、研究成果高效转化等方面存在着较 多不足, 距离形成以自主创新为主导的新兴产业 发展格局尚有较大差距 [8]。

\section{（三）我国科技资源丰富但较为分散}

2018 年, 我国研发经费投入总量近 2 万亿元, 连续多年保持两位数增长, 整体规模稳居世界 第二。大型仪器保有量和科研数据等科技资源全球 领先, 但是资源分散问题仍然没有解决, 未能充分 形成合力。一方面，我国科技管理权限分散在不同 部门, 因而设立了由不同渠道支持建设的多类科研 平台，造成了平台布局分散、财政资金支持分散的 现象, 不能形成合力。另一方面, 面对国内外新形 势, 各省各地区纷纷出台政策措施, 努力推进技术 进步并大力发展战略性新兴产业, 这在一定程度上 取得了成效，但是造成了科技资源的进一步分散， 不能形成集聚效应。

\section{（四）人才激励机制亟待解决}

人才特别是高端人才是首要资源, 战略性新兴 产业发展对人才的需求尤为迫切。自我国实施人才 强国战略以来, 新兴产业发展取得了一系列显著成 就, 与此同时也面临函待解决的问题。在所有面临 的问题中, 最重要的是探索建立与新时代举国科技 体制相适应的人才激励机制和共享机制。还有一些
现象值得反思, 如为了谋求发展, 地方人才竞争和 人才争夺愈演愈烈，出现了政策雷同、政策攀比和 恶性竞争等突出问题。这些问题会在不同程度上导 致人才无序流动、人才资源配置失当、人才发挥效 率低下。

\section{三、战略性新兴产业发展的紧迫性分析}

面对国际激烈竞争态势和我国的发展需要, 加快新时期战略性新兴产业培育与发展显得尤为 迫切。

深刻认识中美博弯的艰巨性和长期性。美国作 为世界唯一的霸权国, 其全球战略的核心目标是确 保美国的世界霸权地位。随着中国经济飞速发展和 快速崛起, 综合国力位列全球第二, 美国全球战略 重心转移到中美战略竞争上来是大概率事件, 将成 为今后较长时期内全球战略博弯的核心内容。有 观点认为, 如果中国在自身具有比较优势的产业 上取得技术进步, 则有利于美国; 如果中国在美 国具有比较优势的产业上取得技术进步，则美国 受损; 随着 $5 \mathrm{G} 、 \mathrm{AI}$ 等领域技术优势的确立, 中 国尝试构建具有竞争优势的高科技产业体系, 中 美之间已然落入 “萨缪尔森陷阱” [9]。因此, 应 对中美博弯的长期性和艰巨性做好充分的准备。

我国迫切需要加快战略性新兴产业发展。经过 多年的高速发展，我国在取得巨大成就的同时，也 面临着资源短缺, 大气、水、土壤严重污染等问题, 转向高质量发展迫在眉睫。高质量发展的重点是推 动产业结构转型升级, 将实体经济做实、做强、做 优。新兴产业是指发展潜力巨大但目前还处于 “苗 头” 或者初步发展阶段的产业类型, 相对传统产 业具有耗能低、污染小、回报高的特点, 是构建经 济发展新动能并提高产业竞争力的重要抓手。战略 性新兴产业除具有新兴产业的基本特征外，还需面 向更长远的经济社会发展需求，做好产业布局，打 好关键基础。鉴于战略性新兴产业的独特定位, 新 时期迫切需要将其作为经济建设重中之重, 加快新 旧动能转化步伐。

加快发展战略性新兴产业是突破 “中等收入陷 阱” 的重要保证。第二次世界大战以来，大多数中 等收入国家陷入了 “中等收入陷阱”, 只有少数中等 
收入国家实现了跨越式发展而成为高收入国家。“中 等收入陷阱” 成为发展中国家进入中等收入阶段后 所必须面对的挑战。按照世界银行 2018 年收入分 组标准, 人均国民总收入低于 1025 美元的为低收 入国家, 在 1026 3995 美元的为中等偏下收入国家, 在 3996 12 375 美元的为中等偏上收入国家, 高于 12376 美元的为高收入国家。据国家统计局统计, 2018 年我国人均国民总收入达到 9732 美元, 接近 中等偏上收入国家的上限。中国是世界上最大的发 展中国家, 自改革开放以来经济快速发展, 创造了 世界奇迹, 但这种发展以粗放型和劳动密集型为主 要特征, 属于不可持续的发展方式。因此, 如何顺 利跨越 “中等收入陷阱” 成为中国必须解决的难题。 通过对日本、韩国成功跨越和拉美国家深陷困境的 案例研究, 以及中国的实际情况分析发现, 升级传 统产业和培育战略性新兴产业是跨越 “中等收入陷 阱”的必然路径 [10]。

\section{四、战略性新兴产业发展思路}

我国战略性新兴产业培育与发展的顶层设计已 经基本完善。在新的发展阶段, 要继续将战略性新 兴产业摆在经济社会发展更加突出的位置, 与传统 产业互相协调、促进融合, 共同构建国家现代产业 体系。在国家现代产业体系框架下, 准确识别出新 兴产业的关键短板技术, 坚持国际合作和自主攻关 “双线并举”。进一步统筹国内资源, 加快战略性新 兴产业区域布局, 助推新兴产业集群化发展。

培育和发展战略性新兴产业, 将之作为国家现 代产业体系中的重要支柱, 进一步优化和明确战略 性新兴产业的范围。目前我国培育和发展的战略性 新兴产业主要包括新一代信息技术、生物、高端装 备制造、新材料、绿色低碳和数字创意等产业。经 过多年发展, 部分产业已经发展壮大, 如 2018 年 我国新能源汽车销量达 125.6 万辆, 占全球市场份 额的一半以上。这类产业应逐步退出战略性新兴产 业行列, 而量子信息科学、战略计算和生产性服务 业等具有战略性和前瞻性的新兴产业应逐步纳入战 略性新兴产业行列, 以进一步提升新兴产业在国家 现代产业体系中的层次和规模。我国的现代产业体 系主要分为传统产业和战略性新兴产业两大类。在
大力发展战略性新兴产业的同时, 鼓励将新兴技术 运用到传统产业领域, 推动新兴产业与传统产业融 合, 进一步提升产业链水平, 促进产业体系迈向全 球价值链的中高端。

做好战略性新兴产业关键短板技术的识别分类 和战略部署。我国是拥有较多工业门类的国家, 因 而产业短板多、关键核心技术多, 不可能同时解决 所有难题。首先, 梳理战略性新兴产业各产业链中 的短板和核心关键技术, 在资源有限的现状下, 对 于需求迫切且能够攻克的核心关键短板技术, 应集 中优势资源予以解决; 对于需要长时间才能突破的 关键短板技术, 应提出分阶段的战略目标部署, 做 到有序实施、逐步推进。其次, 梳理战略性新兴产 业各产业链中的长板以及短板中的长板, 增加国际 产业技术脱钩的难度, 形成既相互依赖又相互制衡 的局面。随着全球化进程不断加快, 全球产业的价 值链、供应链格局已经形成, 全球产业链的相互依 赖关系不断加强。例如, 当前全球贸易额中有 $2 / 3$ 是中间件, 中间件占比越高, 意味着产业链构成和 运行的国际化程度越高, 即 “你中有我、我中有你” 的全球化相互依赖特征加剧, 在客观上大大增加 了技术脱钩的难度和成本。

在国家层面科学谋划战略性新兴产业的区域 布局, 健康培育产业集群。当前, 以京津冀、长江 三角洲、粤港澳大湾区为代表的城市群或大都市圈 已经成为我国汇聚生产要素、带动地区经济增长最 为重要的阵地。在区域一体化水平不断加深的背景 下, 整合区域优势资源、跨省区谋划战略性新兴产 业布局成为可能, 由此破除当前存在的同质化和无 序竞争壁垒。此外, 针对各省、市、自治区提出的 各种类型产业集群, 以及省与省之间, 甚至市与市、 县与县之间都存在的同质化和无序竞争问题, 可以 从两个方面对产业集群进行优化布局：一是立足区 域优势, 开展创新型产业集群和资源型产业集群的 横向布局; 二是开展局省际 (区域) 产业集群、省 级产业集群和特色产业集群的纵向布局。对于省际 （区域）产业集群，应从国家区域发展战略层面出 发, 面向全国范围加以谋划, 构建好跨省协调的体 制机制; 对于省级产业集群, 应立足国家顶层设计 和区域总体布局, 避免资源浪费以及无序竞争导致 的新兴产业产能过剩; 对于特色产业集群, 宜根据 
省内实际情况加以谋划布局。

\section{五、措施建议}

战略性新兴产业的蓬勃发展, 国家政策发挥了 不可替代的作用。10 年来, 我国从调整产业供给结 构、改善产业发展环境和拓展产业市场需求等方面 着力, 出台了人才培养、资金支持、技术支持、公 共服务、目标规划、金融支持、法规规范、产权保 护、税收优惠、政府采购、贸易政策、用户补贴、 应用示范和价格指导等具体措施 [8]。为进一步推 动我国战略性新兴产业健康发展, 建议在新时期重 点关注以下方面。

\section{（一）强化顶层设计, 将战略性新兴产业作为重 要内容纳入国家 “十四五” 规划中, 出台 “十四五” 国家战略性新兴产业发展专项规划}

随着我国经济发展步入新常态和高质量发展 阶段, 经济增长动力从要素驱动转向创新驱动, 需 要进一步强化战略性新兴产业的培育与发展, 继 续在国家 “十四五”规划中突出战略性新兴产业 发展, 并配套出台专项规划, 推动产业结构由中 低端迈向中高端。此外, 创新驱动发展、京津冀 协同发展、长江经济带发展、黄河流域生态保护 和高质量发展、粤港澳大湾区建设、长江三角洲 区域一体化发展等国家战略的发布实施, 有利于 “十四五”战略性新兴产业的布局和发展。在国家 “十四五”规划以及战略性新兴产业发展规划制定 过程中, 要充分考虑如何与国家战略有机结合, 进 一步明确 “十四五” 战略性新兴产业的定位、目标 和任务。在 “十四五” 国家战略性新兴产业规划中 应充分反映国际产业的发展动态和形势变化。在 “十二五” “十三五” 发展的基础上, 紧密结合国家 经济社会发展的宏观需求和科技突破方向, 对已经 列入战略性新兴产业范围的产业进行优化和篎选, 及时部署新产业。

\section{（二）探索新时代举国体制，建立跨省、跨部门的 协调机制，联合实施科技攻关}

对于基础研究和薄弱环节, 特别是一些关键的 短板技术和产业，发挥 “集中力量办大事” 的新型 举国体制优势, 建立跨部门和跨省区的协调机制,
汇聚国家优势科技研发资源以高效实施集中攻关。 探索实践表明，国家实验室作为我国新时代科技举 国体制的新探索, 能够有效整合科技资源以构建新 型国家研究平台。现行的国家实验室建设模式主要 侧重诸多部委层级分散平台的整合, 而在省际优势 资源整合、激发省区积极性方面还需要进一步加强。 为此, 对于基础研究以及关键的短板技术和产业, 建立健全激励考核和动员机制，充分调动各省区的 积极性参与国家实验室的建设，同时保障各省区能 够及时分享到国家实验室产出带来的红利。各省区 的工作重点在于根据自身和区域优势、瞄准国家实 验室产出, 针对性开展产业布局和调整, 推动新兴 产业集群的优化发展。

\section{（三）探索产业人才的新型激励机制，建立健全人 才共享机制}

国内外环境发生了巨大变化, 迫切需要探索与 之配套的人才激励机制。首先从物质层面予以合理 保障, 切实解决产业人才的子女教育、住房和医疗 等基本问题，消除后顾之忧，为其全身心投入产业 创新发展奠定坚实基础。其次从精神层面激发斗志, 全面落实以人为本、尊重创新、创造价值的精神导 向, 提高产业人才的社会地位和认同感; 注重與论 引导, 营造全社会特别是青少年尊重科学、尊重 人才的良好氛围。最后在全国范围内建立产业人 才档案库, 完善人才兼职制度, 构建灵活的人才 共享机制。

\section{参考文献}

[1] 杜传忠, 胡俊, 陈维宣. 我国新一代人工智能产业发展模式与对 策 [J]. 经济纵横, 2018 (4): 41-47.

Du C Z, Hu J, Chen W X. The development model and countermeasures of China's new generation artificial intelligence industry [J]. Economic Review Journal, 2018 (4): 41-47.

[2] 林伯强. 中国新能源发展战略思考 [J]. 中国地质大学学报 (社 会科学版), 2018, 18(2): 76-83.

Lin B Q. Strategic consideration of new energy development in China [J]. Journal of China University of Geosciences (Social Sciences Edition), 2018, 18(2): 76-83.

[3] 陈刚, 宋玉玉. 数字创意产业发展研究 [J]. 贵州社会科学, 2019 (2): 82-88.

Chen G, Song Y Y. Research on the development of digital creative industry [J]. Guizhou Social Sciences, 2019 (2): 82-88.

[4] 任保全, 任优生. 长三角战略性新兴产业发展的演变趋势及增 长质量研究 [J]. 现代经济探讨, 2016 (9): 77-81.

Ren B Q, Ren Y S. Research on the evolution trend and growth 
quality of strategic emerging industries in the Yangtze River Delta [J]. Modern Economic Research, 2016 (9): 77-81.

[5] 张国强, 汤向俊. 区域战略性新兴产业竞争力比较: 以长三角、 珠三角和京津冀为例 [J]. 经济问题探讨, 2012 (8): 42-47.

Zhang G Q, Tang X J. Comparison of the competitiveness of regional strategic emerging industries: Taking the Yangtze River Delta, Pearl River Delta and Beijing-Tianjin-Hebei as examples [J]. Inquiry into Economic Issues, 2012 (8): 42-47.

[6] 朱瑞博. 中国战略性新兴产业培育及其政策取向 [J]. 改革, 2010 (3): 19-28.

Zhu R B. Chinese strategic emerging industries' cultivating and policy tropism [J]. Reform, 2010 (3): 19-28.

[7] 薛澜, 赵静. 走向敏捷治理: 新兴产业发展与监管模式探究 [J]. 中国行政管理, 2019 (8): 28-34.

Xue L, Zhao J. Toward agile governance: The pattern of emerging industry development and regulation [J]. Chinese Public Adminis- tration, 2019 (8): 28-34.

[8] 中国工程科技发展战略研究院. 2020中国战略性新兴产业发展 报告 [M]. 北京: 科学出版社, 2019.

Chinese Institute of Engineering Development Strategies. Report on the development of strategic emerging industries in China in 2020 [M]. Beijing: China Science Publishing \& Media Ltd., 2019.

[9] 苏庆义. 中美 “脱钩” 论与 “萨缪尔森陷阱” [J]. 世界知识, 2019 (15): 52-53.

Su Q Y. The theory of "decoupling" between China and the United States and the "Samuelson Trap" [J]. World Affairs, 2019 (15): $52-53$.

[10] 姚树洁, 韩川. 从技术创新视角看中国如何跨越 “中等收入陷 阱” [J]. 西安交通大学学报 (社会科学版), 2015, 35(5): 1-6.

Yao S J, Han C. How China across the "middle-income trap" from the perspective of technical innovation [J]. Journal of Xi' an Jiaotong University (Social Sciences), 2015, 35(5): 1-6. 